\title{
Estado e Terceiro Setor: uma análise de aproximação
}

\section{Introdução}

O final do século XX traz, para a arena das discussões contemporâneas, os limites e possibilidades de relacionamento entre o Estado em crise e o Terceiro Setor, entendido este como sendo o segmento social difuso que atua entre o Estado e o mercado e reúne um grande número de organizações de natureza jurídica privada e sem fins lucrativos. $\mathrm{O}$ fato de serem registradas como não tendo fins lucrativos abre caminho para um conjunto de benefícios físcais e outros incentivos governamentais, que podem ser pleiteados em nome de ações e projetos de interesse público desenvolvidos por essas organizações. A questão central é caracterizar o que legitima uma ação ou projeto de interesse público.

No Brasil, duas iniciativas recentes procuram aproximar o Estado e o Terceiro Setor, reabrindo a questão do interesse público ou do interesse coletivo:

a) por um lado, tem-se as organizações sociais (OS) nascidas de uma proposta de reforma do Estado, na qual o Estado é o sujeito da própria reforma que é conseqüência de uma crise mais ampla, caracterizada por contornos internacionais e mudanças bastante imprevisíveis e imperativas, em ritmo acelerado. A proposta de reforma coordenada pelo extinto Ministério da Administração e Reforma do Estado (MARE), cujas funções foram absorvidas pelo Ministério do Orçamento e Gestão (MOG) a partir da Medida Provisória n⿳⺈ 1.795, de 1/01/99, compreende um processo de publicização que se traduz num movimento em direção ao Terceiro Setor, mediante o qual é transferida para o setor público não-estatal a produção dos serviços competitivos ou não-exclusivos do Estado, estabelecendo-se

Luiz Carlos Abreu Mendes, mestre em Administração Pública e Governo pela UnB e Técnico de Planejamento e Pesquisa do IPEA 
um sistema de parceria entre o Estado e a sociedade para seu funciona-

mento e controle (cf. Plano Diretor da Reforma do Aparelho do Estado, 1995: 18). Dessa iniciativa resultou a aprovação da lei no 9.637 , publicada no DOU de 18/05/98, que dispõe sobre a qualificação de entidades como organizações sociais, a criação do Programa Nacional de Publicização, dentre outras providências;

b) por outro lado, tem-se uma iniciativa do Conselho da Comunidade Solidária, que reuniu representantes do governo e de parcelas da sociedade, na $6^{\mathrm{a}}$ Rodada de Interlocução Política sobre o Marco Legal do Terceiro Setor, para discutir a melhoria das relações do Estado com as organizações não-estatais que desenvolvem atividades de interesse público. A idéia central era avançar em direção ao reconhecimento e qualificação de um segmento disperso que pretende dar conta de um vastíssimo conjunto de OS, nem estatais nem mercantis, geradas por iniciativa da comunidade

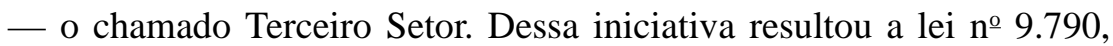
publicada no DOU de 24/03/99, que dispõe sobre a qualificação de pessoas jurídicas de direito privado, sem fins lucrativos, como organizações da sociedade civil de interesse público (OSCIP), institui e disciplina o termo de parceria, dentre outras providências.

As reflexões aqui desenvolvidas detêm-se no contexto e nas motivações que levaram os dois grupos a essas iniciativas, determinando o alcance e limites de cada uma delas. Nesse sentido, examinar os pontos em comum e as diferenças das propostas requer um grande esforço reflexivo, dado o número de fatores internos e externos envolvidos no estudo comparativo, que passam pelo significado político, sócio-econômico e cultural da emergência do Terceiro Setor no Brasil e suas relações históricas e atuais com o Estado. As origens e conformação do Terceiro Setor nos darão, ainda, indícios do que o aproxima e/ou o diferencia dos setores tradicionais público e privado.

\section{Um pouco da história de conformação do Terceiro Setor no Brasil}

Para tentar compreender a lógica de funcionamento do Terceiro Setor é preciso conhecer as condições em que se deu a sua formação no Brasil, as forças motivadoras e o perfil dos dirigentes das entidades e os grupos que dele fazem parte. A dificuldade em recuperar a memória dos primeiros tempos sobre o papel e o desempenho do voluntariado, do associativismo ou da filantropia, no Brasil, está no fato de que essas questões nunca foram alvo privilegiado de discussões na sociedade, nem de 
atenção sistemática por parte dos historiadores. A visibilidade dessas

entidades dá-se de forma fragmentada e descontínua, à sombra de outras questões trabalhadas nas relações, um tanto quanto problemáticas, entre o Estado e a sociedade e entre o público e o privado.

Landim (1993: 12) recupera parte da história, identificando a complexidade em resgatar acontecimentos tão diversificados e dispersos, e faz uma leitura a partir do Período Colonial, examinando os quatro séculos em que a vida social, política e econômica brasileira teve como eixo as grandes unidades agrícolas para exportação:

"Cria-se a sociedade das grandes fazendas, formadas pela casagrande e a senzala, a capela, o canavial, o engenho de produzir o açúcar, as casas dos empregados e eventuais moradores não escravos: mundos relativamente fechados regidos pela lógica patriarcal de dominação senhorial. Os homens livres, nessa sociedade, ocupam um lugar marginal, secundário, tanto social como economicamente. Para sobreviver nesse contexto de relações pessoalizadas era preciso estabelecer e atualizar relações de dependência baseadas em alianças de reciprocidades verticais - o clientelismo — onde se troca individualizadamente proteção e favores por lealdade e serviços.

O segundo traço a ressaltar é o papel da Igreja Católica na configuração dessa sociedade. Basta lembrar que, por quase quatro séculos — até a proclamação da República, em 1889 — vigorou no Brasil o regime de padroado concedido pelo papado à coroa portuguesa. (...) Portanto, durante a maior parte da história do Brasil, o catolicismo foi a religião oficial do Estado. (...) A Igreja Católica que se implantou no Brasil via Portugal foi uma peça fundamental na legitimação do poder político do Estado colonizador, contribuindo para a consolidação dessa sociedade colonial de perfil patriarcal e autoritário."

Nesse contexto, Landim aponta obstáculos para emergir e se consolidarem associações voluntárias e autônomas que visassem a prestação de serviços de caráter público. A Igreja terá um papel fundamental na gestação de quaisquer espaços, iniciativas e valores ligados ao que se pode chamar de atividades filantrópicas na época colonial. Onde havia, nos primeiros séculos da colonização, organizações encarregadas da assistência social, do ensino, da saúde, encontrar-se-á relacionada, a Igreja — com o mandato do Estado - na sua promoção.

Essa configuração deixou marcas e traços que permaneceram presentes na conformação da sociedade brasileira. As mudanças institucionais e políticas que se darão até as primeiras décadas do século XX respondem, na verdade, pelas adaptações sucessivas aos interesses dos grupos 
de dominação representados por uma força política atrelada às grandes fazendas e à Igreja. Landim (op. cit.: 26) destaca a influência determinante da Igreja, por exemplo, no período da Revolução de 30 e do Estado Novo, quando analisa as relações do Estado com as entidades sem fins lucrativos da época:

"Apesar de não o formular em termos de uma política clara, reservaram em seu projeto centralizador e autoritário um papel às entidades sem fins lucrativos, sobretudo, como se viu, as religiosas, nos vários campos das políticas públicas. Recebem isenções, incentivos fiscais e financiamento governamental, escolas religiosas, hospitais e obras sociais ligadas a igrejas — afinal, o que mais se estrutura em termos de assistência e prestação de serviços públicos até os anos 30. Valeria ressaltar também a presença, nesse universo filantrópico, de entidades fundadas por colônias de imigrantes ou de estrangeiros, como as escolas alemãs, francesas, americanas, ou hospitais de grande porte como a Beneficência Portuguesa, o Sírio Libanês, etc."

Passando a um período mais recente da história político-administrativa brasileira, temos, a partir da segunda metade da década de 50, as condições para a conformação do segmento da sociedade que começou a ganhar as características que o trazem para as discussões da crise contemporânea, com a denominação de Terceiro Setor.

No intervalo entre a ditadura populista de Getúlio e a ditadura militar, a sociedade civil brasileira começou a reorganizar-se com projetos de associativismo relativamente autônomos e acentuadamente políticos, onde um grande número de associações civis e os sindicatos, formalmente atrelados ao Estado, terão um papel significativo. Nascem, a partir daí, lideradas pela classe média intelectualizada e militante, seguindo uma tendência generalizada na América Latina, as organizações que virão a ser conhecidas por ONGs (Organizações Não-Governamentais), as quais exercerão uma liderança fundamental na caracterização e conformação do Terceiro Setor.

As ONGs irão se defrontar, no Brasil, com o regime de força iniciado com o golpe de Estado em 1964, ocupando espaços de atuação em meio à sociedade civil, com projetos de curto alcance, ou de pouca visibilidade, e com a presença marcante da Igreja Católica que, naquele momento, estava dividida: os segmentos mais conservadores, que iriam assumir a Conferência Nacional dos Bispos do Brasil (CNBB), apoiavam os militares no combate aos comunistas ateus; por outro lado, o Concílio Vaticano II e a CNBB de 1962 sinalizavam uma renovação pastoral. A partir do final da década de 50, já se destacavam alguns atores da Igreja, como a Juventude 
Universitária Católica (JUC) e a Juventude Operária Católica (JOC), realizando trabalhos de reaproximação entre a Igreja e a sociedade brasileira. Parcela significativa de dirigentes brasileiros das chamadas ONGs, de primeira geração, teve sua formação comunitária atuando nessas organizações.

Recorre-se, novamente, a Landim (op. cit.: 31) para examinar as relações da Igreja com o regime militar:

“(...) após 68, com o endurecimento do regime, quando agentes religiosos são atingidos pela repressão, a Igreja reagirá como corpo e sua hierarquia passará a assumir uma posição definida de crítica e oposição ao regime. A CNBB, antes dividida, acaba por convergir na posição de defesa das liberdades civis e dos direitos humanos, afirmando a liberdade face ao Estado e promovendo a tradução da doutrina social cristã em princípios de ação pastoral, através de inúmeros documentos. As Comissões de Justiça e Paz e os diversos Centros de Defesa dos Direitos Humanos criados pelo País sob a inspiração da Igreja, tornam-se um emblema na luta contra a tortura, contra a censura, pela liberdade dos presos políticos e pela democracia."

Todos esses movimentos antiditadura/antigoverno iriam delinear uma postura e uma lógica de organização e atuação que se tornaram a marca registrada das instituições do Terceiro Setor das décadas de 70 e 80, passando a ser reconhecidas como ONGs na década de 90.

Parece ser característico do Terceiro Setor, em todas as épocas, a espontaneidade e a diversidade; mas a multiplicação de iniciativas privadas com sentido, interesse ou caráter público, na forma como hoje as reconhecemos é, definitivamente, um fenômeno recente e global. Assim, na dinâmica própria do segmento, o assistencialismo e filantropia praticados até a década de 60 passam por um período de rejeição a partir dos anos 70, quando se dá, com maior ênfase, o surgimento do associativismo de caráter independente (da Igreja e do Estado) e politizado. No final da década de 80, com a redemocratização do País, as ONGs mais antigas iniciam um processo de revisão do escopo, âmbito e forma de atuação, que irá resultar numa aproximação, ainda que relutante a princípio, com o governo e com o mercado. A partir de 85, o número de ONGs no Brasil se multiplica com outras características, não necessariamente políticas, atuando em nichos cada vez mais especializados: saúde, defesa de minorias, defesa da mulher, meio ambiente etc.

A década de 90 traz novidades ainda maiores ao incorporar instituições e formas organizacionais diferentes, tornando a sua configuração e consolidação mais complexa e difusa. O Conselho da Comunidade Solidária (1997: 3) aponta a diversificação do Terceiro Setor e reforça a necessidade de conhecer melhor os atores e organizações que dele fazem parte, sinalizando para a abrangência atual do segmento em expansão: 
"Na década de 80 foram as ONGs que, articulando recursos e experiências na base da sociedade, ganharam alguma visibilidade, enquanto novos espaços de participação cidadã. Hoje, percebemos que o conceito de Terceiro Setor é bem mais abrangente. Inclui o amplo espectro das instituições filantrópicas dedicadas à prestação de serviços nas áreas de saúde, educação e bem-estar social. Compreende também as organizações voltadas para a defesa dos direitos de grupos específicos da população, como mulheres, negros e povos indígenas, ou de proteção ao meio ambiente, promoção do esporte, cultura e lazer. Engloba as experiências de trabalho voluntário, pelas quais cidadãos exprimem sua solidariedade através da doação de tempo, trabalho e talento para causas sociais. Mais recentemente, temos observado o fenômeno crescente da filantropia empresarial, pela qual as empresas concretizam sua responsabilidade social e o seu compromisso com melhorias nas comunidades."

É nesse contexto de ampliação e consolidação do Terceiro Setor, que surgem as duas propostas apresentadas a seguir.

\section{A proposta do extinto Ministério da Administração e Reforma do Estado (MARE)}

O marco referencial do programa de reforma administrativa protagonizado pelo MARE é o Plano Diretor da Reforma do Aparelho do Estado (1995), que identifica a crise brasileira da última década como uma crise do modelo de desenvolvimento adotado pelos governos anteriores, desviando o Estado de suas funções básicas, o que teria agravado a crise fiscal e, por conseqüência, a inflação.

A questão da crise do Estado é trazida para a contemporaneidade dos últimos 20 anos, destacando-se a aceleração do desenvolvimento tecnológico e da globalização da economia mundial. Nestes termos, o Plano Diretor da Reforma do Aparelho do Estado (1995: 15) parte do reconhecimento da falência do modelo vigente, de alcance universal, e caracteriza, assim, a crise do Estado:

“1) uma crise fiscal, caracterizada pela crescente perda do crédito por parte do Estado e pela poupança pública que se torna negativa;

2) o esgotamento da estratégia estatizante de intervenção do Estado, a qual se reveste de várias formas: o Estado do bem-estar social nos países desenvolvidos, a estratégia de substituição de importações, no terceiro mundo e, o estatismo nos países comunistas; e, 
3) a superação da forma de administrar o Estado, isto é, a superação da administração pública burocrática."

O Plano Diretor, após uma breve retrospectiva da reforma administrativa promovida pelo Departamento Administrativo do Serviço Público (DASP), a partir de 1936, cita as distorções do período militar (1964-85), compara a flexibilidade proposta pelo decreto-lei no $200 / 67$ ao que denominou “engessamento" imposto pela Constituição de 88, e, a partir dessas considerações, levanta questões que orientarão a nova proposta:

- O Estado deve permanecer realizando as mesmas atividades? Algumas delas podem ser eliminadas? Ou devem ser transferidas da União para os estados ou para os municípios? Ou ainda, devem ser transferidas para o setor público não-estatal? Ou então para o setor privado?

- Por outro lado, dadas as novas funções, antes reguladoras que executoras, deve o Estado criar novas instituições?

- Para exercer as suas funções, o Estado necessita do contingente de funcionários existente? A qualidade e a motivação dos servidores é satisfatória? Dispõe-se de uma política de recursos humanos adequada?

- As organizações públicas operam com qualidade e eficiência? Seus serviços são voltados, prioritariamente, para o atendimento do cidadão, entendido como um simples cliente, ou estão mais orientadas para o simples controle do próprio Estado?

Examina, tendo por base esse questionamento, as dimensões institucional-legal e de recursos humanos vigentes na administração pública federal e questiona a situação atual do mercado de trabalho no setor público, sob a ótica da crise fiscal e gastos com pessoal, da evolução e desequilíbrio nas remunerações dos servidores públicos, da dimensão cultural e da dimensão do modelo de gestão. Revê, ainda, os setores de atuação do Estado e as formas de propriedade, para então, propor uma configuração organizacional diferente, que pressupõe a adoção de novos modelos institucionais e gerenciais.

O Plano Diretor (op. cit.: 56) objetiva, precipuamente, aumentar a governança do Estado, ou seja, sua capacidade administrativa de governar com efetividade e eficiência, voltando a ação dos serviços do Estado para o atendimento dos cidadãos. Estabelece, para tanto, limites às funções consideradas próprias do Estado e propõe a transferência de parte dos serviços hoje prestados diretamente, pelos órgãos da administração pública federal, para outras instituições, sejam elas da iniciativa privada, de propriedade pública não-estatal, ou de outras instâncias de governo (estaduais ou municipais).

Para reverter as condições de ineficiência do aparelho do Estado e reforçar a governança, o Plano (op. cit.: 19) propõe uma transição programada de um tipo de administração pública burocrática, rígida e ineficiente, 
voltada para si própria e para o controle interno, para uma administração pública gerencial, flexível e eficiente, voltada para o atendimento do cidadão. Condiciona, porém, a reforma do Estado à redefinição do seu papel, que deixa de ser o responsável direto pelo desenvolvimento econômico e social, pela via da produção de bens e serviços, para fortalecer-se na função de promotor e regulador desse desenvolvimento.

Estas noções irão determinar o escopo da proposta de reforma, que se baseia na divisão do aparelho do Estado em quatro setores, estabelecidos pelo Plano Diretor (op. cit.: 52-3):

- núcleo estratégico, onde são definidos os instrumentos reguladores e as políticas públicas e que tem, ainda, o papel de cobrar o seu cumprimento; a ele correspondem os Poderes Legislativo e Judiciário, o Ministério Público e, no Poder Executivo, o Presidente da República, os ministros e seus auxiliares e assessores diretos, responsáveis pelo planejamento e formulação das políticas públicas;

- atividades exclusivas, onde são prestados serviços que só o Estado pode realizar. São serviços ou agências em que se exerce o poder extroverso do Estado: de regulamentar, fiscalizar, fomentar. Como exemplos, cita a cobrança e fiscalização dos impostos, a polícia, a previdência social básica, o serviço de desemprego, a fiscalização do cumprimento de normas sanitárias, o controle do meio ambiente, o subsídio à educação básica, o serviço de emissão de passaportes, entre outros;

- serviços não-exclusivos, setor onde o Estado atua, simultaneamente, com outras organizações públicas não-estatais e privadas. O modelo da proposta prevê que as instituições desse setor não possuem o poder de Estado, embora este se faça presente porque os serviços envolvem direitos humanos fundamentais, como os da educação e da saúde, ou porque possuem economias externas relevantes, na medida que produzem ganhos que não podem ser apropriados por esses serviços através do Estado. Como exemplos, cita as universidades, os hospitais, os centros de pesquisa e os museus;

- produção de bens e serviços para o mercado, que corresponde à área de atuação das empresas. Algumas dessas atividades que ainda permaneciam no Estado, como por exemplo as de infra-estrutura, estão sendo, gradativamente, privatizadas. No Brasil, todo o setor de telecomunicações acaba de ser terceirizado, resultando na maior privatização já realizada no mundo, com valor superior a 20 bilhões de dólares.

É no setor de serviços não-exclusivos do Estado que se encontram as OS. Através do processo de publicização, nasceram as primeiras OS, regulamentadas pela lei no 9.637 , de 15/05/98.

O MARE apresenta, assim, as OS (1998: 13-5): 
“As OS são um modelo de organização pública não-estatal destinado a absorver atividades publicizáveis mediante qualificação específica. Trata-se de uma forma de propriedade pública não-estatal, constituída pelas associações civis sem fins lucrativos, que não são propriedade de nenhum indivíduo ou grupo e estão orientadas, diretamente, para o atendimento do interesse público.

As OS são um modelo de parceria entre o Estado e a sociedade. O Estado continuará a fomentar as atividades publicizadas e exercerá sobre elas um controle estratégico: demandará resultados necessários à concretização dos objetivos das políticas públicas. O contrato de gestão é o instrumento que regulará as ações das OS. (...)

As OS constituem uma inovação institucional, embora não representem uma nova figura jurídica, inserindo-se no marco legal vigente, sob a forma de associações civis sem fins lucrativos. Estarão, portanto, fora da administração pública, como pessoas jurídicas de direito privado. A novidade será de fato a sua qualificação, mediante decreto, como OS, em cada caso.

Qualificada como OS, a entidade estará habilitada a receber recursos financeiros e a administrar bens e equipamentos do Estado. Em contrapartida, ela se obrigará a celebrar um contrato de gestão por meio do qual serão acordadas metas de desempenho que assegurem a qualidade e a efetividade dos serviços prestados ao público."

\section{A proposta do Conselho da Comunidade Solidária}

O Conselho da Comunidade Solidária foi criado em fevereiro de 1995, ocasião em que tomaram posse os primeiros conselheiros, sendo: 21 membros da sociedade civil, 10 ministros de Estado e a secretária-executiva do programa Comunidade Solidária. Em junho de 1996, após uma crise interna que resultou na saída de dois conselheiros, foi decidida uma reestruturação do Conselho, que levasse em conta a necessidade de promover canais políticos de diálogo entre o governo e a sociedade sobre os grandes temas relacionados à estratégia de desenvolvimento social para o Brasil. Entre outros programas e atividades protagonizados pelo Conselho, nasce, a partir daí, o processo de interlocução política que estabelece objetivos, decide pela construção de consensos e identificação de dissensos e adota uma metodologia de trabalho simples e objetiva, embora trabalhosa, para o alcance dos seus propósitos. Tal metodologia resulta de uma série de reuniões realizadas com a preocupação de definir uma estratégia de desenvolvimento social para o Brasil, que passa a ter os seguintes pontos principais: 
- Objetivo político geral: contribuir para a construção de um acordo ou entendimento estratégico nacional em torno de uma agenda mínima de prioridades, medidas, instrumentos e procedimentos de ação social do Estado e da sociedade para o enfrentamento da fome, da miséria, da pobreza e da exclusão social.

- Objetivos específicos: estimular soluções, agilizar e acompanhar a implementação de providências, contribuir para remover obstáculos e superar impasses que comprometem, delongam ou tiram a eficácia das ações que devem ser empreendidas.

- Construção de consensos: a interlocução política deve procurar construir, progressivamente, consensos sobre temas centrais de uma agenda mínima social e identificar e listar os dissensos existentes numa pauta para a continuidade do processo de diálogo governo-sociedade.

A Sexta Rodada de Interlocução Política do Conselho da Comunidade Solidária foi inteiramente dedicada ao tema "Marco Legal do Terceiro Setor", objetivando, por um lado, identificar as principais dificuldades legais que as entidades privadas não-mercantis enfrentam no seu cotidiano e, por outro, recolher sugestões de como reformar a atual legislação e inovar.

O processo teve início com o encaminhamento de um documentode-consulta a 66 interlocutores: os conselheiros da Comunidade Solidária (11 ministros de estado e 21 representantes da sociedade civil); a secretária-executiva do programa Comunidade Solidária; o secretário de Coordenação da Câmara de Política Social do Governo; e mais 32 interlocutores especialmente convidados — representantes de ONGs, assessores do governo de áreas afins com a temática a ser trabalhada, estudiosos do assunto. As respostas desse conjunto de pessoas foram reunidas num documento chamado "Coletânea de Contribuições", que procurou trabalhar os consensos relativos aos problemas e encaminhar as propostas de soluções sugeridas, tais como foram originalmente formuladas. Esse novo documento, na sua primeira versão como documento-base, foi encaminhado a todos os interlocutores para sociabilizar as contribuições e apresentar eventuais emendas. A incorporação das modificações propostas deu origem à segunda versão do documento-base, que foi, então, submetida à apreciação do Conselho da Comunidade Solidária, na sua XVII reunião. As contribuições enviadas foram agrupadas em cinco consensos potenciais (Marco Legal do Terceiro Setor, 1998: 21-7):

1) O papel estratégico do Terceiro Setor: o fortalecimento do Terceiro Setor, no qual se incluem as entidades da sociedade civil de fins públicos e não-lucrativas, constitui hoje uma orientação estratégica nacional, em virtude da sua capacidade de gerar projetos, assumir responsabilidades, empreender iniciativas e mobilizar recursos necessários ao desenvolvimento social do país. 
2) A mudança do marco legal do Terceiro Setor: o fortalecimento de Terceiro Setor exige que seu marco legal seja reformulado.

3) A abrangência do Terceiro Setor: a reformulação do marco legal exige a construção de um entendimento mais amplo sobre a abrangência do próprio conceito de Terceiro Setor.

4) Transparência e responsabilidade do Terceiro Setor: a expansão e fortalecimento do Terceiro Setor é responsabilidade, em primeiro lugar, da própria sociedade, a qual deve instituir mecanismos de transparência e responsabilização capazes de ensejar a construção de sua auto-regulação.

5) O Estado e o Terceiro Setor: a reformulação do marco legal exige que o estabelecimento de direito seja acompanhado pela contrapartida de obrigações das entidades do Terceiro Setor para com o Estado, quando estiverem envolvidos recursos estatais.

Foram ainda reunidas as propostas de consensos específicos, com os respectivos encaminhamentos sugeridos, em oito áreas temáticas (op. cit.: 31-47): registros e cadastros administrativos; contratos e convênios; mecanismos de auto-regulação; mecanismos institucionais de responsabilização; doações; regulamentação do voluntariado; contrato de trabalho por prazo determinado; informações.

Constituíram-se, então, três grupos de trabalho, com prazo de 120 dias, com a finalidade de gerar propostas de soluções para os consensos agrupados nos grandes temas, reunindo representantes do governo, da sociedade e conselheiros do Comunidade Solidária.

Com relação aos temas "registros e cadastros administrativos" e "contratos e convênios", os trabalhos do grupo resultaram na promulgação da lei $\mathrm{n}^{\mathrm{0}}$ 9.790, de 23/03/99, que simplifica o reconhecimento institucional das entidades sem fins lucrativos, além de abrigar várias das novas formas sociais de organização da sociedade e fomentar o controle social e a responsabilização das organizações. Foi também regulamentado o termo de parceria, por meio do decreto $\mathrm{n}^{\mathrm{o}} 3.100$, de 30/06/99, que permite a negociação de objetivos e metas entre as partes e, também, o monitoramento e a avaliação dos resultados dos projetos, instrumento equivalente ao contrato de gestão criado para as OS, na proposta do MARE.

Com relação à área temática "mecanismos de auto-regulação" foi considerado que as iniciativas, nesse sentido, deveriam partir das organizações da sociedade civil, sem qualquer interveniência governamental.

Com relação à área temática "regulamentação do voluntariado" foi decidido acompanhar e apoiar a aprovação de um projeto de lei que se encontrava em tramitação no Congresso Nacional, à época - hoje, lei no 9.608, de 18/02/98 —, além de apoiar duas outras iniciativas: a) Programa Nacional de Promoção do Trabalho Voluntário no Brasil; b) criação de programas governamentais de Serviço Civil. 
Finalmente, com relação à área temática “informações”, foi decidido

apoiar a consolidação e expansão da Rede de Informações do Terceiro Setor (RITS), em funcionamento na cidade do Rio de Janeiro e gerida por uma entidade sem fins lucrativos.

\section{As possibilidades de parceria entre o Estado e o Terceiro Setor}

A partir das duas propostas e considerando o contexto de expansão, diversificação e consolidação do Terceiro Setor, passa-se a examinar as suas relações com o Estado.

O ecletismo do Terceiro Setor é positivo, por um lado, porque revela o pluralismo das formas de atuação comunitária; mas por outro lado, aponta lógicas de intervenção social e modalidades de articulação externa muito distintas, o que dificulta a sua identidade.

Entende-se que o Governo Federal, ao criar o processo de publicização, amplia o ecletismo do segmento, gerando uma nova categoria de organizações que contraria uma lógica importante de atuação histórica do Terceiro Setor: a autonomia de suas entidades em relação ao Estado. A lei no 9.637 estabelece que as organizações qualificadas como OS, pelo Estado, serão por este subsidiadas, com autonomia relativa, para desenvolver atividades em áreas prioritárias.

Por outro lado, a iniciativa do Conselho da Comunidade Solidária, com participação e apoio de representações do Terceiro Setor, qualifica organizações já existentes na sociedade civil, propondo mecanismos que simplifiquem as relações com o Estado, identificando uma crise que não é só do Estado, mas também da sociedade e, como parte dela, do Terceiro Setor.

Aproximar o aparelho do Estado de organizações da sociedade significa examinar os interesses e formas de atuação comuns, ainda que reconhecendo o fato de que suas ações resultem da aplicação de princípios e lógicas diferentes. Nesse sentido, há registros de iniciativas do Estado, em todas as esferas de governo, de Norte a Sul do País, mostrando não ser privilégio do Terceiro Setor trabalhar na dimensão da cooperação, da solidariedade e da democracia, o que leva às seguintes considerações:

- A quem interessa a aproximação entre o Estado e o Terceiro Setor?

- Quem se beneficia e se fortalece com o processo de publicização proposto pela reforma do aparelho do Estado?

- Quem se beneficia e se fortalece com a proposta de reconhecimento e qualificação das entidades já existentes no Terceiro Setor, de iniciativa do Conselho da Comunidade Solidária? 
- O que há de redundante, de complementar e de exclusivo, nas duas propostas?

O argumento do Plano Diretor da Reforma do Estado é claro: a crise do Estado exige uma redefinição do papel do mesmo, não para minimizá-lo, mas para fortalecê-lo na função de promotor e regulador do desenvolvimento. O processo de publicização é um mecanismo importante de implementação da proposta e foi pensado, inicialmente, para contemplar as áreas de educação, saúde, cultura e pesquisa científica.

A lei n⿳9 9.637/98 ampliou os limites das áreas de interesse, incluindo meio ambiente e desenvolvimento tecnológico. Importantes, mas, ainda com abrangência insuficiente no tratamento das questões sociais. Conseqüentemente, ficam de fora uma gama de funções contempladas pela lei $\mathrm{n}^{\mathrm{o}}$ 9.790/99, como sendo de interesse público — defesa e promoção de direitos humanos, da ética, da paz, da democracia, da cidadania e de outros direitos universais, para citar alguns - o que inviabiliza, pelo processo de publicização, a parceria com organizações do Terceiro Setor que tratam dessas questões, até porque, quando o fazem, é para chamar a atenção do Estado que não está dando-lhes o tratamento adequado.

A proposta do MARE impõe, além disso, uma lógica intervencionista do Estado: não se trata de reconhecer um Terceiro Setor existente, procurar reforçá-lo e regulamentá-lo. Nela, o Estado promove a extinção de organizações, até então estatais, e transfere patrimônio, pessoal e recursos financeiros para uma nova instituição de direito privado, sem fins lucrativos, que assume as atividades, antes, de responsabilidade direta do Estado. A flexibilidade administrativa prevista, o modelo gerencial por resultados e o contrato de gestão podem vir a melhorar a eficiência e eficácia dessas entidades, mas não as transformam em organizações do terceiro setor. Nem mesmo seria um quarto setor, mas uma outra modalidade de atuação do Estado, inovadora e importante.

Neste ponto, torna-se inevitável reportar-se a Faoro (1992: 8 e 18), que provoca uma discussão interessante entre a modernização e a modernidade de um país:

“...a modernização chega à sociedade por meio de um grupo condutor que procura moldar sobre o país, pela ideologia ou pela coação, uma certa política de mudança (...) traduz um esquema político para uma ação fundamentalmente política, mas economicamente orientada; por outro lado, caso o movimento, se de modernidade se trata, não é um reflexo, nem meramente uma transição, mas um processo que não depende de comandos externos para se realizar."

Tem-se, a partir dessa reflexão, que a mudança necessária não pode partir de uma ideologia e de uma vontade unilateral do Estado pois, 
neste caso, à sociedade restaria apenas receber as diretrizes quanto ao tipo de Estado e de sociedade que podem ser criados e desenvolvidos. A modernidade, nos termos da argumentação do autor, é algo que decorre da emancipação social, do compartilhamento de idéias e propostas que representam o amadurecimento possível de cada sociedade, em razão dos seus valores, da sua história e da sua capacidade de agir para, então, rever tudo e avançar. Não existem atalhos no processo.

Reforça-se a noção de que é necessário estar atento aos valores, princípios e forças motoras que mobilizam e configuram o Estado, o mercado e o Terceiro Setor, para perceber melhor em que se complementam, se assemelham e diferenciam, para não confundi-los ou tentar impor-lhes idéias equivocadas de participação e de responsabilização. Considere-se, nesse sentido, o que Santos (1998: 16) denomina os princípios que regem o Estado, o mercado e o Terceiro Setor.

Partindo da idéia geral de que a emergência do Terceiro Setor viria completar a tríade na composição de forças reguladoras do social na modernidade ocidental, o autor desenvolve o argumento de que a lógica de funcionamento do Terceiro Setor estaria subordinada ao que denominou princípio da comunidade, que afirma a obrigação política horizontal e solidária de cidadão a cidadão, ao contrário da lógica do Estado, que tem por princípio a obrigação política vertical entre cidadãos e Estado.

Quanto à lógica do mercado, lembra Santos (id.: 18), esta se apoiou sempre no princípio empresarial do lucro, que não dá sinais de fraqueza, nem parece afetado pela crise. Pelo contrário, Santos reconhece uma total hegemonia atual do mercado que passou, inclusive, a permear áreas da sociedade civil até agora poupadas à incivilidade do mercado como, por exemplo, a cultura, a educação, a religião, a administração pública, a proteção social, a produção e gestão de sentimentos, atmosferas, emoções, ambientes, gostos, atrações, repulsas, impulsos.

Outros estudiosos reforçam as reflexões de Santos e levantam a possibilidade de que o ressurgimento e fortalecimento do Terceiro Setor, no final deste século, seria a oportunidade para o princípio da comunidade comprovar as suas vantagens comparativas em relação ao princípio do mercado e ao princípio do Estado, os quais teriam falhado nas respectivas tentativas de hegemonizar a regulação social em períodos anteriores recentes.

Santos (ibid.: 17) chama atenção, porém, para a superficialidade dessa leitura e questiona a capacidade do Terceiro Setor em assumir esse papel:

"Em primeiro lugar, não é tão claro que estejamos perante um duplo falhanço, do Estado e do mercado; em segundo lugar, a existir tal falhanço, é ainda menos claro que o princípio da comunidade, depois de um século de marginalização e de colonização por parte 
do Estado e do mercado, tenha ainda a autonomia e energia necessárias para protagonizar uma nova proposta de regulação social, mais justa, capaz de repor a equação entre regulação e emancipação sociais, que constitui a matriz originária da modernidade ocidental."

Neder (1996:1) destaca outros elementos a considerar na redefinição dos papéis e limites do Estado, do Terceiro Setor e do mercado:

"Identificar no terceiro setor um potencial de inclusão social e política no quadro da cidadania parece correto como tendência internacional. Interpretação totalmente diversa e equivocada é tomar as entidades da sociedade civil como responsáveis pela inclusão econômica do excluído. Essa é tarefa para o sistema político, junto com as agências governamentais e o empresariado."

A crise contemporânea do Estado, concordando com Santos, é uma crise do reformismo social, representada, precipuamente, pela crise das formas políticas de atuação do Estado, dominantes no período do Estado desenvolvimentista. Discorda, como ele, das teses dos extremistas da globalização de que seja uma crise generalizada e o fim do Estado. Nesse sentido, lembra que o caráter repressivo do Estado, o seu protagonismo nos processos de regionalização supranacional e de liberalização da economia mundial, a sua função previdencial facilitadora e protetora em relação a empresas privadas que desempenham funções consideradas de interesse público, nada disso parece atravessar qualquer crise. Em favor dessa opinião, tem-se no caso brasileiro, o papel relevante e inalienável do Estado, ainda que por vezes precário, nas questões de segurança interna e externa, nas negociações no Mercosul, na liberalização controlada de importações, na regulação dos incentivos e isenções fiscais para organizações do mercado e do Terceiro Setor, sem deixar de reconhecer que a crise global mais recente tenha revelado fraquezas e dependências externas relevantes.

Qualificando melhor, o que está em crise no Estado é o seu papel na promoção de intermediações não-mercantis entre cidadãos, onde vigora o princípio da obrigação política horizontal e solidária de cidadão a cidadão, próprio da lógica de atuação do Terceiro Setor. A dificuldade do Estado é, pois saber, como desempenhar essa função mediadora, com os mecanismos que dispõe - a política fiscal e as políticas sociais — sem perder identidade (lógica de atuação) e capacidade de intervenção.

Os macroelementos conceituais e analíticos, até agora abordados, fundamentam as reflexões mais pontuais sobre a forma de reconhecimento e inserção do Terceiro Setor na reforma do Estado, a partir das propostas aqui examinadas:

- As duas propostas sinalizam que a saída para a falência do modelo político de intervenção do Estado é a valorização da sociedade civil, chamando-a para discutir e resolver em parceria as questões sociais relevantes 
e inadiáveis. Uma forma de fazê-lo é reconhecer a relevância das ações desenvolvidas pelas chamadas organizações privadas sem fins lucrativos, qualificando, porém, melhor, as que atuam, de fato, no interesse do público.

- Por conta disso, interessa ao Estado, aproximar-se do Terceiro Setor, onde se configura a parte mais organizada e atuante da sociedade. Fazê-lo através do processo de publicização, com a qualificação das OS, é válido, desde que reconhecidos e respeitados os limites impostos pela identidade e lógica de funcionamento do Terceiro Setor. A forma de constituição das OS e os mecanismos de regulação geram uma dependência em relação ao Estado que é incompatível com o modus vivendi das organizações do Terceiro Setor. Essa dependência fará com que as OS estejam mais preocupadas em atender às prioridades de governo, o que, não necessariamente, coincide com as prioridades da sociedade, apesar dos cuidados anunciados, porque é o Estado que garante a dinâmica e a manutenção institucional das OS. Essa questão não é resolvida por decreto governamental, o que não invalida a proposta do Plano Diretor da Reforma do Aparelho do Estado, no que diz respeito à lei no 9.637. A iniciativa, voltase a dizer, é importante para a racionalização das funções do Estado, melhoria dos serviços prestados e, por conseqüência, melhoria das relações com a sociedade, mas não torna as OS parte integrante do Terceiro Setor; nem se precisa disso.

- Há dificuldades quando as duas propostas, mediante os mecanismos e instrumentos próprios de controle - contrato de gestão, no caso das OS e termo de parceria, no caso das OSCIP — procuram definir quais as melhores entidades. Por um lado, é reconhecido pelas lideranças do Terceiro Setor que, no segmento, há entidades filantrópicas. Por outro lado, a publicização prevê a melhoria dos serviços hoje prestados pelo Estado, ou seja, pressupõe a ineficiência de organizações estatais que deverão passar à condição de OS. Pela sua natureza e âmbito de atuação, esse processo terá oportunidade de desenvolver um controle de resultados mais efetivo, via contrato de gestão, do que o processo de qualificação das OSCIP, via termo de parceria, este último de amplitude maior e mais difusa. O risco, no caso da publicização, é que as decisões sejam orientadas por interesses político-partidários ou sejam uma demonstração do prestígio pessoal de dirigentes governamentais. É uma oportunidade para negar este pressuposto e ser mais seletivo e imparcial.

- O processo de publicização sinaliza benefícios de médio prazo para o Estado, na medida em que se espera redução de custos decorrentes da implementação do modelo de gestão gerencial. Beneficia-se, a médio prazo, também, a sociedade, se tudo der certo. O contrato de gestão, instrumento referencial de acompanhamento e validação do modelo, é necessário, mas precisa ser reconhecido como um protocolo de intenções, sujeito às imponderabilidades endógenas e exógenas que fogem ao controle 
das partes contratantes. As OS herdarão uma cultura organizacional burocrática, cujos vícios precisam ser enfrentados e superados, o que também não se resolve por decreto. O Estado, preso às condições e limites impostos pela globalização da economia, sequer pode garantir o cumprimento da liberação dos recursos orçamentários previstos no contrato de gestão, além das dificuldades ditadas pelo jogo de forças políticas.

- As OSCIP, quando assim qualificadas, precisarão assumir um compromisso com a efetividade de suas ações, atentando para a praticidade dos resultados, ainda que em detrimento de modelos ideais e ideológicos. Por parte do Estado, há necessidade de criar mecanismos e instrumentos legais capazes de estimular e atrair a parceria com as OSCIP. É uma oportunidade para o Estado e a sociedade reconhecerem seus limites e possibilidades, e assim amadurecer e avançar, sem medo de errar, sem demagogia.

- Em contraponto à proposta do MARE, na qual as OS têm o papel de entidades executoras das políticas públicas definidas e avaliadas pelos órgãos do núcleo estratégico, as discussões promovidas pelos representantes de alguns segmentos do Terceiro Setor formado, principalmente, pelas chamadas ONGs politizadas de primeira geração, insistem em dois pontos: a) querem ter um papel relevante na formulação das políticas e na vigilância de sua efetividade; b) não admitem substituir o Estado em funções por eles consideradas inalienáveis, embora aceitem o papel de complementaridade.

- No Plano Diretor, o Estado diz buscar, no Terceiro Setor, a substituição (transferência subsidiada) de suas ações, para viabilizar um espaço público não-estatal. Há três possibilidades de articulação entre o Estado e o Terceiro Setor: a confrontação, a complementaridade e a substituição. Admitindo que a fase de confrontação, predominante no período da ditadura militar, não é hoje desejada e priorizada por quaisquer das partes, é preciso examinar as outras duas modalidades. A complementaridade entre o Terceiro Setor e o Estado é reconhecida, nos países democráticos, como a outra grande via de criação de um espaço público não-estatal, onde a parceria pressupõe a soma de esforços, identificando os limites e possibilidades dos parceiros. A substituição, por sua vez, assenta-se na distinção entre funções exclusivas e funções não-exclusivas do Estado. Por trás dessa distinção está, na proposta do MARE, a idéia de que, sempre que o Estado não demonstre ter uma vantagem comparativa, deve ser substituído, no exercício das funções não-exclusivas, por instituições privadas mercantis (privatização) ou do terceiro setor (publicização). Santos (op. cit.: 43) considera essa distinção altamente problemática, sobretudo porque a análise da gênese do Estado moderno revela que nenhuma das funções do Estado foi, originalmente, exclusiva dele; a exclusividade do exercício de funções foi sempre 
o resultado de uma luta política. Não havendo funções essencialmente exclusivas não há, por implicação, funções essencialmente não-exclusivas.

- Por outro lado, é evidente o apoio de parcelas do Terceiro Setor à iniciativa do Conselho da Comunidade Solidária que resultou no projeto de lei que regulamenta as relações do Estado com as chamadas OSCIP. O aval revela um crédito recíproco na tentativa de aproximação do Estado com o Terceiro Setor. É também verdade que os dois lados consideram insuficiente essa legislação, mas a reconhecem como um primeiro passo na melhoria das relações.

- Neste caso, o Terceiro Setor, assumindo a função de complementaridade, sai fortalecido, de imediato, porque tem reconhecida uma reivindicação antiga, de simplificação da burocracia, exigida para legitimar as parcerias com o Estado; a médio prazo, espera pela efetivação de outras medidas regulamentares. O Estado sai fortalecido ao ganhar a confiança, ainda que parcial e relativa, dos subconjuntos do Terceiro Setor reconhecidos pela legislação. Os que se sentirem excluídos pressionarão para terem os benefícios que, eventualmente, vierem a ser conquistados pelas OSCIP.

Tudo indica que as duas legislações são importantes e complementares, mas algumas questões gerais e fundamentais ainda estão para serem respondidas:

- Que recursos (humanos, financeiros, tecnológicos, organizacionais, gerenciais, políticos, ideológicos) dispõe o Terceiro Setor, para a contribuição esperada ou desejada na superação da crise do Estado?

- Como compatibilizar eficiência e eficácia com eqüidade e cidadania ativa?

- A experiência brasileira do Estado-mercado, do período desenvolvimentista, não vale como reflexão para a proposta do Estado-Terceiro Setor, como solução para a crise atual?

- Tem-se a dimensão das transformações em processamento e que afetam, indistintamente, os atores (sujeito e objeto) envolvidos nas articulações e negociações das mudanças desejadas?

Do meu ponto de vista, essas transformações são tão profundas que, sob a mesma designação de Estado, está a emergir uma nova forma de organização política mais vasta do que o Estado, da qual o Estado é o articulador e integrante de um conjunto híbrido de fluxos, redes e organizações, onde se combinam e se interpenetram elementos estatais e não-estatais, nacionais, locais e globais (Santos, 1998: 36). 
Comunidade Solidéria. (1997), "O Conselho da Comunidade Solidária e a Construção de Novas Relações entre Estado e Sociedade no Brasil - O Governo e o Terceiro Setor". XV Reunião do Conselho. Brasília: Granja do Torto, 30/06/97. (mimeo).

DECRETO № 3.100. (30/06/99), publicado no DOU de 1/07/99 e republicado, por incorreções, no DOU de 13 de julho de 1999, seção 1.

FAORO, Raymundo. (1992), “A questão nacional: a modernização”. Estudos avançados, 6(14). São Paulo.

Landim, Leilah. (1993), "Para Além do Mercado e do Estado? Filantropia e Cidadania no Brasil". Série Textos de Pesquisa. Rio de Janeiro: ISER, Núcleo de Pesquisa.

LEI № 9.608. (18/02/98), publicada no DOU de 19/02/98, Seção 1, dispõe sobre o serviço voluntário e dá outras providências.

LeI № 9.637. (15/05/98), publicada no DOU de 18/05/98, Seção 1, dispõe sobre a qualificação de entidades como organizações sociais, a criação do Programa Nacional de Publicização e extinção dos órgãos e entidades que menciona e a absorção de suas atividades por organizações sociais, e dá outras providências.

LeI № 9.790. (23/03/99), publicada no DOU de 24/03/99, Seção 1, dispõe sobre a qualificação de pessoas jurídicas de direito privado, sem fins lucrativos, como organizações da sociedade civil de interesse público, institui e disciplina o termo de parceria, e dá outras providências.

Marco legal do terceiro Setor. (1998), Cadernos Comunidade Solidária, n. 5, Brasília: IPEA.

Neder, Ricardo Toledo. (1996), "Sociedade Civil e Terceiro Setor”, Jornal Folha de São Paulo: Caderno Opinião, 1-3, sexta feira, 4/10/96.

Organizações SociaIs. (1998), Cadernos MARE da Reforma do Estado, n. 2, 4. ed. Brasília: MARE.

Presidência da República. (1995), Plano Diretor da Reforma do Aparelho do Estado. Brasília: Câmara da Reforma do Estado, Ministério da Administração e Reforma do Estado, MARE.

SAntos, Boaventura de Sousa. (1998), "A Reinvenção Solidária e Participativa do Estado". Texto apresentado no Seminário Internacional "Sociedade e Reforma do Estado". Brasil. (mimeo). 


\section{Estado e terceiro setor: uma análise de duas iniciativas de aproximação \\ Luiz Carlos Abreu Mendes}

$\mathrm{O}$ artigo examina duas iniciativas recentes de aproximação do Governo Federal (a do extinto Ministério da Administração e Reforma do Estado e a do Conselho da Comunidade Solidária) com o chamado Terceiro Setor. Comparam-se as legislações que regulamentam e legitimam as duas propostas, com foco nos elementos-chave que destacam as peculiaridades e determinam as lógicas regentes de cada iniciativa.

\section{Estado y tercero sector: una análisis de dos iniciativas de aproximación \\ Luiz Carlos Abreu Mendes}

Este trabajo analiza dos iniciativas recientes de acercamiento del Gobierno Federal (la del extinto Ministerio de la Administración y Reforma del Estado y la del Consejo de la Comunidad Solidaria) hacia el llamado tercer sector. Son comparados el marco legal que regulamenta y legitima las dos propuestas, enfocando en los elementos clave que muestran las peculiaridades y que determinan las lógicas que rigen cada una de las iniciativas.

\section{State and third sector: an analysis of two initiatives in approximation}

Luiz Carlos Abreu Mendes

The article describes two recent initiatives of the Federal Government (one of the extinguished Ministry for Management and Reform of the State and the one of the Council of Solidarity Community) to approach the so called third sector. The paper compares the legislation which serves as framework for and legitimates the two governmental proposals, focusing on the key elements which give these initiatives importance and distinctive features.
Revista do

Serviço

Público

Ano 50

Número 3

Jul-Set 1999

Luiz Carlos

Abreu Mendes, mestre em Administração Pública e

Governo pela UnB e Técnico de Planejamento e Pesquisa do IPEA 